\title{
Factors Affecting the Detection of an Imperiled and Cryptic Species
}

\author{
John A. Crawford ${ }^{1, *(\mathbb{D}, \text { Michael J. Dreslik }}{ }^{2}$, Sarah J. Baker ${ }^{2}$, Christopher A. Phillips ${ }^{2}$ and \\ William E. Peterman ${ }^{3}$ D \\ 1 National Great Rivers Research and Education Center, East Alton, IL 62024, USA \\ 2 Illinois Natural History Survey, Prairie Research Institute, University of Illinois, Champaign, IL 61820, USA; \\ dreslik@illinois.edu (M.J.D.); sbaker@azgfd.gov (S.J.B.); caphilli@illinois.edu (C.A.P.) \\ 3 School of Environment and Natural Resources, Ohio State University, Columbus, OH 43210, USA; \\ Peterman.73@osu.edu \\ * Correspondence: joacrawford@lc.edu; Tel.: +1-618-468-2838
}

Received: 2 April 2020; Accepted: 29 April 2020; Published: 1 May 2020

\begin{abstract}
Population surveying and monitoring are important for identifying conservation needs and tracking trends in populations, communities, and ecosystems over time and laying the groundwork for conservation management and policy decisions. If species or populations go undetected because of inadequate effort or sampling design, protection and management cannot be properly provided. Due to the widespread loss of populations, the Eastern Massasauga (a rattlesnake) was recently listed as a federally threatened species in the United States; it is also listed as threatened in Canada. Given its current conservation status, there is considerable interest at state and federal levels in determining how to best survey for Eastern Massasaugas to aid in management decisions. Using a 16-year dataset, we examined the relationships among environmental, temporal, area, management, and search effort factors on the detection probability of Eastern Massasaugas. We found that four abiotic parameters (solar irradiance, shaded air temperature, three-day maximum air temperature, and humidity) and three search parameters (effort per researcher, search area, and search time of day) influenced detection of Eastern Massasaugas. As the current biodiversity crisis continues, the cost-effective use of resources and scientific expertise will continue to increase in importance. We hope our results stimulate similar analyses in other taxa, which will be critical for designing and implementing regional survey and monitoring programs.
\end{abstract}

Keywords: Eastern Massasauga; endangered; grassland; management; monitoring; rattlesnake; Sistrurus catenatus

\section{Introduction}

Surveying and monitoring are important for tracking temporal trends in populations, communities, and ecosystems, and they lay the groundwork for conservation management and policy decisions [1]. However, surveying for rare, imperiled, and/or cryptic species can be a challenging task [2,3] because a large amount of effort may be required to determine presence/absence at a single location, let alone across a species' range [4]. If inadequate sampling design or effort result in false negatives, populations may not receive the protection and management needed to persist [4,5]. Consequently, determining the appropriate design and effort required to evaluate status and trends of imperiled and cryptic species is a vital first step for surveying and monitoring programs [6,7].

Reptiles are undergoing global declines due to habitat loss and alteration, disease, global climate change, environmental pollution, and overharvesting for the pet trade [8-10]. Over the past decade, the number of reptiles on the IUCN (International Union for Conservation of Nature) Red List doubled, 
and approximately $21 \%$ of reptile species are considered vulnerable to extinction [11]. Although many snake species are of conservation concern [12], conservation status assessments are hampered for over $80 \%$ of the species because they remain unevaluated or are data-deficient [11]. For example, in Illinois, United States of America (USA; where our study was conducted), approximately $40 \%$ of all snake species are currently listed as Species in Greatest Conservation Need [13].

We are only beginning to understand the varied roles snakes play in aquatic and terrestrial systems [14-17], but snake declines can have negative consequences on ecosystem structure and function [18]. Our general lack of information stems from their cryptic behavior, minimal activity patterns, and use of inaccessible (e.g., subterranean, arboreal) habitats [19-21]. Furthermore, such ecological traits result in a deficiency of high-resolution distribution and status data, which can obscure range-wide trends [22,23].

Establishing true presence/absence for non-imperiled snake species within a specified area can require substantial effort [4]. When population declines are suspected, it is challenging to separate absence from poor sampling without incorporating detection probabilities [24,25]. This challenge is particularly true for cryptic and imperiled taxa such as snakes, which led to increased interest in estimating and accounting for detection probability over the past decade [26,27]. With a known detection probability, one can determine the number of survey events required to detect a species with a given level of confidence [28]. Furthermore, incorporating survey-level covariates can help explain variation in detection estimates and provide insight into the factors that must be accounted for when surveying for a target species [27]. Once the number of surveys required to assess presence/absence is confidently established, researchers can then determine how many sites can be surveyed given the resources available (i.e., time, money). Prioritizing survey efforts during conditions associated with high detection can ensure accurate occupancy designation or improve abundance estimates. Such data are valuable for imperiled species.

Thus, the objective of our work studying a cryptic and imperiled snake was to determine the relationship among environmental, temporal, area, management, and search effort factors and the detection probability of the Eastern Massasauga (Sistrurus catenatus). Determining the factors associated with species detection aids in maximizing the amount of information per dollar spent on conservation efforts and provides an estimate of the number of searches required to achieve a certain confidence of true absence. Our results also provide further refinement of the optimal conditions and methods for conducting surveys to maximize survey efficiency, which will increase confidence in presence/absence determinations and reduce bias in the number of individuals encountered.

\section{Materials and Methods}

\subsection{Study Species and Sites}

The Eastern Massasauga (Sistrurus catenatus) is a small rattlesnake ranging from southern Ontario and central New York west to Iowa and Missouri [29]. The geographic distribution of extant localities is fragmented because of range-wide extirpations [30]. Thus, the Eastern Massasauga is listed as endangered or threatened in every state it occurs except Michigan, where it is a species of special concern [30]. Recently, the Eastern Massasauga was listed as threatened under the United States Endangered Species Act of 1973 [31,32]. In Canada, they are listed as threatened under Canada's Federal Species at Risk Act [33]. Given its current conservation status, there is considerable interest at state and federal levels in determining how to best survey for Eastern Massasaugas to aid management decisions.

We conducted our study at Carlyle Lake (Clinton County) located in south-central Illinois, USA (38.62 ${ }^{\circ}$ north $(\mathrm{N}), 89.35^{\circ}$ west $(\mathrm{W})$ ). Carlyle Lake is a $\sim 10,500$-ha human-made impoundment (1967). The lake is surrounded by $\sim 4500$ ha consisting of remnant grasslands, wetlands, and upland and bottomland forests [34]. We conducted our searches in 13 grassland hibernacula patches at four public sites: (i) Dam East Recreation Area (DERA); (ii) Dam West Recreation Area (DWRA); (iii) Eldon Hazlet State Park (EHSP); and (iv) South Shore State Park (SSSP). DERA and DWRA are owned and 
maintained by the United States Army Corps of Engineers (USCOE), whereas EHSP and SSSP are owned and maintained by the Illinois Department of Natural Resources (IDNR).

Although S. catenatus do not communally hibernate like many other rattlesnakes, they do aggregate in wet grassland habitats and over-winter in crayfish burrows. This artificial inflation of densities affords easier access to large numbers of individuals. Thus, all visual encounter surveys occurred during the emergence period which ranged from late February until mid-May depending on general climatic conditions (earlier spring weather resulted in searches conducted in late February, and late or cooler spring conditions extended searching into mid-late May). Searches consisted of surveyors spread approximately 2-3 m apart walking parallel transect lines through suitable grassland habitat. We constrained search areas between physical habitat boundaries such as roadways, woodland edges, and other urban and recreational land features. To vary the amount of effort spent per site, we attempted to vary search times by either increasing or decreasing the number of parallel transects run. During each survey, searchers would scan the ground, search in brush piles (as encountered), and intermittently move vegetation with snake hooks in areas where vegetation was dense. Upon encountering a snake, all searching and time recording stopped until snake-specific data was collected.

\subsection{Environmental Variables}

We used surveys conducted from 1999-2014 having complete data for the analysis. At the start and end of each search, we recorded shaded air temperature $\left({ }^{\circ} \mathrm{C}\right)$, substrate temperature $\left({ }^{\circ} \mathrm{C}\right)$, relative humidity $(\%)$, and wind speed $(\mathrm{m} / \mathrm{s})$ using a Kestrel $®$ pocket weather meter. We then generated two additional variables representing the change in shaded air temperature and change in substrate temperature during the search period. From the local weather station at the US Army Corps of Engineers office $\left(38.62^{\circ} \mathrm{N}, 89.38^{\circ} \mathrm{W}\right)$, we collected the previous day minimum, maximum, and mean air temperatures $\left({ }^{\circ} \mathrm{C}\right)$, as well as the previous three-day average of the minimum, maximum, and mean air temperatures $\left({ }^{\circ} \mathrm{C}\right)$. We calculated the area (ha) of suitable habitat searched using geographic information system (GIS) data layers, ground-truthing, and then summing the area searched. For solar irradiance, we used the modeled solar radiation on a horizontal surface received from the sky from the National Solar Radiation Database (http://nsrdb.nrel.gov). The irradiance data were derived from the Physical Solar Model ver. 3 at $4 \times 4 \mathrm{~km}$ resolution around the approximate coordinates between all study sites (38.61-89.34). Finally, for use in the analysis, we aggregated the solar data to represent the maximum solar radiation by day. We also collected historical burn data for all sites from the land managers and coded the variable as burn (if a full or partially controlled burn occurred at the search site in a given year) and no burn (if no controlled burns occurred at the search site). For search effort related variables, we recorded the number of searchers and the total search time (minutes), and we then calculated the mean search time per searcher ( $\mathrm{min}$ ). Finally, we converted the date of searches into day of the year. Because all variables were on different scales, we standardized them using a $z$-transformation; thus, they are represented as standard deviates. Summaries and explanations of all variables used are presented in Table 1.

\subsection{Multicollinearity Assessment}

To minimize multicollinearity and its negative effects on parameter estimates, we firstly used pair-wise correlation analysis to view correlations among variables. Then, we used ridge regression to determine which parameter estimates were unstable given some perturbation (penalization) using the lm.ridge function in the MASS package of $R[35,36]$. Briefly, ridge regression imparts a penalty term $(\lambda)$ on $\beta$ parameter estimates. In situations with multicollinearity, if $\beta$ parameter estimates show large changes (numerically or directionally), they are unstable. For example, if we observed multicollinearity in the suite of variables describing the previous day's temperature, we would only use one representative variable from the suite per model. Once we removed all offending variables, we performed a second ridge regression to ensure no unstable variables remained. If multicollinearity effects persisted, we iteratively repeated the process until our reduced variable had stable $\beta$ parameter estimates. 
Our correlation analysis revealed substantial associations between the three-day and previous day mean, min, and max temperatures and warranted caution using them in the same candidate models (Figure S1, Supplementary Materials). Our initial ridge regression analysis revealed the following parameters were unstable: eSAT, eSUB, dSAT, dSUB, eWind, and eHUM. We eliminated those variables from subsequent analyses. We resolved all parameter instability from our variable set in our second (and final) ridge regression analysis, and all parameter estimates remained stable regardless of the penalty used (Table S1, Figure S2, Supplementary Materials).

Table 1. Environmental, temporal, and effort variables used in the analysis of Eastern Massasauga searches conducted at Carlyle Lake, Clinton County, Illinois, from 1999-2014 with descriptions and units of measurement. Variables with a quadratic (squared) term included are represented by an asterisk.

\begin{tabular}{|c|c|c|}
\hline Variable & Description & Unit \\
\hline dSICA* & Presence or absence of an Eastern Massasauga in a search & binary \\
\hline rTime & $\begin{array}{l}\text { Time calculated as the relative time of day on a } 24 \text {-hour basis (hour }+ \\
\qquad \text { minute/ } 60+\text { second/360)/24 }\end{array}$ & $\mathrm{h}$ \\
\hline DayofYear & Day of the year the search was conducted & count \\
\hline sArea & $\begin{array}{l}\text { The total area of grassland that habitat searches were conducted } \\
\text { in/patch size }\end{array}$ & ha \\
\hline Burn & Whether or not a burn was conducted in the search area & binary \\
\hline nSearch* & Number of searchers per search & count \\
\hline mEffort* & Mean effort per searcher (tEffort/nSearch) & $\min$ \\
\hline tEffort* & Total search effort per search (cumulative time per searcher) & $\min$ \\
\hline Precip & Precipitation for the day of searching & $\mathrm{cm}$ \\
\hline $\mathrm{daRad}^{*}$ & Historic solar irradiance data & $\mathrm{J} / \mathrm{s} \cdot \mathrm{m}^{2}$ \\
\hline sHum* & Relative humidity at the ground level as the start of searching & $\%$ \\
\hline eHum* & Relative humidity at the ground level as the end of searching & $\%$ \\
\hline sWind & Wind speed $\sim 1.5-2 \mathrm{~m}$ above ground level at the start of searching & $\mathrm{m} / \mathrm{s}$ \\
\hline eWind & Wind speed $\sim 1.5-2 \mathrm{~m}$ above ground level at the end of searching & $\mathrm{m} / \mathrm{s}$ \\
\hline sSAT ${ }^{*}$ & Shaded air temperature at the start of searching & ${ }^{\circ} \mathrm{C}$ \\
\hline eSAT $^{*}$ & Shaded air temperature at the end of searching & ${ }^{\circ} \mathrm{C}$ \\
\hline $\mathrm{dSAT}^{*}$ & Change in shaded air temperature during searching (sSAT - eSAT) & ${ }^{\circ} \mathrm{C}$ \\
\hline sSUB ${ }^{*}$ & Substrate temperature $\sim 2 \mathrm{~cm}$ in the substrate at the start of searching & ${ }^{\circ} \mathrm{C}$ \\
\hline eSUB ${ }^{*}$ & Substrate temperature at the end of searching & ${ }^{\circ} \mathrm{C}$ \\
\hline dSUB* & Change in substrate temperature during searching (sSUB - eSUB) & ${ }^{\circ} \mathrm{C}$ \\
\hline pMean* & Mean temperature for the previous day & ${ }^{\circ} \mathrm{C}$ \\
\hline $\mathrm{pMax}^{*}$ & Maximum temperature for the previous day & ${ }^{\circ} \mathrm{C}$ \\
\hline pMin* & Minimum temperature for the previous day & ${ }^{\circ} \mathrm{C}$ \\
\hline p3Mean* & Average mean temperature for the previous three days & ${ }^{\circ} \mathrm{C}$ \\
\hline p3Max* & Average maximum temperature for the previous three days & ${ }^{\circ} \mathrm{C}$ \\
\hline p3Min* & Average minimum temperature for the previous three days & ${ }^{\circ} \mathrm{C}$ \\
\hline
\end{tabular}

\subsection{Statistical Analyses}

Because Eastern Massasaugas occupied all our search sites, we could focus on factors affecting detection probability. Thus, we employed mixed-effects, binary logistic models using the glmer function in the lme4 R package [37] on the full dataset. Our dependent variable was the presence or absence of Eastern Massasaugas during the search, and our random effect was the site. Using our reduced variable set (multicollinearity analysis above), we constructed 25 a priori models including a global and null intercept-only model (Table 2). We also included quadratic terms for some variables because of the potential to exhibit non-linearities (Table 2). We assessed model fit following an information theoretic approach [38] using the AICcmodavg package [39]. Because our goal was to present the best predictive model for detection probability, we also constructed one post hoc model based on the $\beta$ parameter estimates with confidence intervals not bounding zero from the global model and one model for land managers using readily obtained variables. We used the effects package to examine the responses of detection probabilities to the covariates [40,41]. Finally, we used the piecewiseSEM package in $\mathrm{R}$ to calculate the conditional and marginal $r^{2}$ values for the two highest ranked models [42]. To assess the predictive capacity of our models, we estimated the area under the curve (AUC) and constructed response operator curves (ROC) for the top and global models for comparisons. 
Table 2. Candidate model parameterizations used for the detection probability and capture yield analyses. All logistic detection models included a random effect of site.

\begin{tabular}{|c|c|c|}
\hline Model & Variables & Description \\
\hline Global & All Variables & Global additive \\
\hline Null & Intercept & Intercept only \\
\hline 3DayTemps & m3Min, m3Max, m3Mean & Recent temperature \\
\hline Burn & Burn & Habitat management \\
\hline Calendar & rTime, DayofYear & Seasonality \\
\hline EvapCooling & sHUM, sWind, sSAT, Precip, daRad & Evaporative cooling \\
\hline m3Mean + daRad & m3Mean, daRad & Recent mean temps \\
\hline m3Mean + Precip & m3Mean, Precip & Recent mean temps and precipitation \\
\hline m3Min + daRad & m3Min, daRad & Recent min temps \\
\hline m3Min + Precip & m3Min, Precip & Recent min temps and precipitation \\
\hline tEffort + Burn & tEffort, Burn & Search effort and management \\
\hline tEffort + sArea & tEffort, sArea & Search effort and area \\
\hline tEffort + sArea + Burn & tEffort, sArea, Burn & Effort, area, and management \\
\hline PDayTemps & pMin, pMax, pMean & Previous days temps \\
\hline pMean + daRad & pMean, daRad & Previous mean and radiation \\
\hline pMean + Precip & pMean, Precip & Previous mean temp and precipitation \\
\hline pMin + daRad & pMin, daRad & Previous min and radiation \\
\hline pMin + Precip & pMin, Precip & Previous min and precipitation \\
\hline ProximateTemps & sSUB, sSAT & Proximate temps \\
\hline SearchEffort & tEffort, nSearch, sArea & Total effort \\
\hline sSUB + Burn & sSUB, Burn & Substrate and management \\
\hline sSUB + daRad & sSUB, daRad & Substrate and radiation \\
\hline sSUB + Precip & sSUB, Precip & Substrate and precipitation \\
\hline sSUB + sArea & sSUB, sArea & Substrate and area \\
\hline sSUB + sArea + Burn & sSUB, sArea, Burn & Substrate, area, and management \\
\hline post hoc Additive & Burn, sSUB, m3Min, rTime, mEffort, daRad & post hoc \\
\hline Manager Additive & Burn, sSUB, m3Min, rTime, mEffort & Manager variables \\
\hline
\end{tabular}

\subsection{Conservation Applications}

We used the Manager model to construct a tool in Microsoft Excel, which allows user input Burn, planned starting time (rTime), sSUB, m3Min, and mEffort. For flexibility, we allowed mEffort to be user input from nSearch and planned tEffort. We designed the detection tool to provide the estimates and confidence intervals for the detection/non-detection probabilities and their associated $95 \%$ confidence intervals. To obtain the number of searches, we modified the following equation from MacKenzie and Royle [28]:

$$
p^{*}=1-(1-p)^{k},
$$

where $p^{*}$ is the of detecting a species at least once, $p$ is the observed detection probability, and $k$ is the number of surveys; we then solved for $k$ as follows:

$$
k=\frac{\ln \left(-p^{*}+1\right)}{\ln (1-p)}
$$

We then applied the detection model to a historic Eastern Massasauga dataset to estimate the probability of a false negative (occupied site but no detections). Although the detection probability does not typically suffer from false positives with trained surveyors, true negatives (snakes are not present) and false negatives (snakes are present but missed) comprise the non-detection probability. For the analyses, we conservatively assumed that non-detection always represented false negatives (occupied sites) and, thus, the product of the non-detections becomes the overall probability of missing Eastern Massasaugas from every survey. The historical data we used comprised 58 search events over four years $(2008,2009,2010$, and 2015) for a grassland site in the Chicago, Illinois, USA, region (Table S3, Supplementary Materials). We generated m3Min data from the National Climate Data Center website (ncdc.noaa.gov) using the nearest weather station where we could get data for all dates (O'Hare International Airport, Chicago, Illinois, USA, 41.96, -87.93). We summarized solar radiation data from the same coordinates as the weather station data as above (Section 2.2). Finally, we took the 
product of the non-detection probabilities by year and all surveys to generate the probability Eastern Massasaugas were present but not detected in any of the surveys.

\section{Results}

\subsection{Data Composition}

Our initial dataset comprised 895 individual search events from 1999-2014 across 13 hibernacula at four state/federally owned properties. We had 400 S. catenatus detections (44.6\%), which illustrated that, although a rare species, our data neither had too few nor too many detections. We removed 182 surveys which were missing some covariate data. Many of these removed surveys were from the first few years of the study when we were iteratively improving our search design and, thus, added or removed variables. This narrowed the range of years from 2002-2014. The final data comprised 713 independent survey events (Table S2, Supplementary Materials) with most (632 surveys) occurring at the two IDNR properties (EHSP and SSSP) followed by the two USCOE properties (DERA and DWRA). We always placed maximal effort on SSSP because it also serves as our reference population for determining demographic patterns. Our final dataset had 315 S. catenatus detections across the 713 search events $(44.2 \%)$, illustrating that the removal of survey events that were missing data did not impact the proportion of detections per survey.

\subsection{Factors Affecting Detection Probabilities}

Of the 27 mixed-effects binary logistic models we examined, the best model was the post hoc model, which carried an Akaike weight of 0.83 (Table 3). Variables included in the model were Burn, daRAD, mEffort, rTime, sSUB, m3Min, and all associated quadratic terms (Table 4). The post hoc model explained a high amount of variance in detection probabilities $\left(r^{2}\right.$ cond $=0.40$; Table 3$)$ with most of the variance explained by the fixed effects $\left(r^{2}\right.$ marg $=0.28$; Table 3$)$. The Manager model excluding daRad also had strong support and carried an Akaike weight of 0.17 with a higher amount of variance explained $\left(r^{2}\right.$ cond $=0.39$; Table 3$)$ mostly by the fixed effects $\left(r^{2}\right.$ marg $=0.27$; Table 3$)$. The global model, with 30 parameters estimated, had little support and did not carry any appreciable Akaike weight; it was $\sim 15.0 \triangle \mathrm{AIC}_{\mathrm{C}}$ (AIC = Akaike information criterion) units away from the top model (Table 3). The global model explained only a bit more overall variance $\left(r^{2}\right.$ cond $=0.47$; Table 3$)$, again, with most of the variance explained by the fixed effects $\left(r^{2}\right.$ marg $=0.33$; Table 3$)$. For reference, the null model was the second to last model carrying no appreciable Akaike weight and being $\sim 102 \triangle \mathrm{AIC}_{\mathrm{C}}$ units away from the top model (Table 3). The post hoc model had a high AUC value $(0.82,95 \%$ confidence interval $(\mathrm{CI})=$ $0.79,0.85)$ and, thus, good predictive capacity, as well as the Manager model $(0.82,95 \% \mathrm{CI}=0.78,0.84)$, whereas not much of that capacity was lost in the reduction of factors when compared to the AUC of the global model $(0.82,95 \% \mathrm{CI}=0.78,0.84$ : Figure 1$)$. 
Table 3. Akaike information criterion (AIC) results for the 27 binary mixed-effect logistic regressions for detection probability models. Data were collected from 713 search events on the Eastern Massasauga at Carlyle Lake, Clinton County, Illinois from 1999-2014.

\begin{tabular}{lcccccccc}
\hline Rank & Model & $\mathbf{K}$ & $-\mathbf{2 L L}$ & $\mathbf{A I C}_{\mathbf{C}}$ & $\boldsymbol{\Delta} \mathbf{A I C}_{\mathbf{C}}$ & $\boldsymbol{\omega}_{\mathbf{i}}$ & $\boldsymbol{r}^{2}{ }_{\text {marg }}$ & $\boldsymbol{r}_{\text {cond }}$ \\
\hline 1 & post hoc & 13 & -399.65 & 825.82 & 0.00 & 0.83 & 0.28 & 0.40 \\
2 & Manager & 11 & -403.31 & 828.99 & 3.17 & 0.17 & 0.27 & 0.39 \\
3 & Global & 30 & -389.07 & 840.87 & 15.05 & 0.00 & 0.33 & 0.47 \\
4 & tEffort + Burn & 5 & -416.62 & 843.33 & 17.51 & 0.00 & 0.25 & 0.34 \\
5 & tEffort + sArea + Burn & 6 & -415.90 & 843.92 & 18.10 & 0.00 & 0.25 & 0.35 \\
6 & SearchEffortAdd & 6 & -418.55 & 849.21 & 23.39 & 0.00 & 0.23 & 0.35 \\
7 & tEffort + sArea & 5 & -420.73 & 851.55 & 25.72 & 0.00 & 0.22 & 0.33 \\
8 & Calander & 7 & -444.23 & 902.62 & 76.79 & 0.00 & 0.11 & 0.33 \\
9 & sSUB + sArea + Burn & 7 & -450.72 & 915.61 & 89.78 & 0.00 & 0.08 & 0.31 \\
10 & sSUB + Burn & 6 & -452.62 & 917.36 & 91.54 & 0.00 & 0.06 & 0.29 \\
11 & m3Min + daRad & 6 & -453.60 & 919.32 & 93.50 & 0.00 & 0.03 & 0.28 \\
12 & sSUB + daRad & 7 & -452.58 & 919.33 & 93.50 & 0.00 & 0.04 & 0.31 \\
13 & sSUB + Precip & 6 & -453.84 & 919.81 & 93.98 & 0.00 & 0.03 & 0.29 \\
14 & 3DayTemps & 9 & -450.85 & 919.96 & 94.14 & 0.00 & 0.04 & 0.29 \\
15 & m3Min + Precip & 7 & -452.94 & 920.03 & 94.21 & 0.00 & 0.04 & 0.29 \\
16 & sSUB + sArea & 6 & -454.19 & 920.50 & 94.68 & 0.00 & 0.03 & 0.29 \\
17 & m3Mean + daRad & 7 & -454.20 & 922.56 & 96.73 & 0.00 & 0.03 & 0.28 \\
18 & pMin + Precip & 6 & -455.34 & 922.79 & 96.97 & 0.00 & 0.02 & 0.26 \\
19 & ProximateTemps & 7 & -454.74 & 923.65 & 97.82 & 0.00 & 0.03 & 0.28 \\
20 & m3Mean + Precip & 6 & -455.87 & 923.86 & 98.03 & 0.00 & 0.02 & 0.26 \\
21 & pMin + daRad & 7 & -455.15 & 924.45 & 98.63 & 0.00 & 0.03 & 0.27 \\
22 & Burn & 4 & -458.28 & 924.62 & 98.80 & 0.00 & 0.03 & 0.25 \\
23 & pMean + Precip & 6 & -456.38 & 924.87 & 99.05 & 0.00 & 0.02 & 0.25 \\
24 & PDayTemps & 9 & -453.71 & 925.67 & 99.85 & 0.00 & 0.03 & 0.27 \\
25 & pMean + daRad & 7 & -456.24 & 926.64 & 100.82 & 0.00 & 0.02 & 0.26 \\
26 & Null & 3 & -461.16 & 928.36 & 102.53 & 0.00 & 0.00 & 0.24 \\
27 & EvapCooling & 10 & -457.74 & 935.79 & 109.96 & 0.00 & 0.01 & 0.26 \\
\hline
\end{tabular}

The six variables comprising the post hoc model illustrates that we surveyed under a range of conditions (Table 4, Figure 2). Of our total surveys, 383 occurred in burned/semi-burned habitats and 330 occurred in burned habitats. Surveys were completed under conditions centered with a daRad $\approx$ $800 \mathrm{~J} / \mathrm{s} \cdot \mathrm{m}^{2}, \mathrm{rTime} \approx$ midday, $\mathrm{sSUB} \approx 18^{\circ} \mathrm{C}, \mathrm{m} 3 \mathrm{Min} \approx 6^{\circ} \mathrm{C}$, and $\mathrm{mEffort} \approx 50 \mathrm{~min}$ (Table 4 ; Figure 2).

Whether a site received a burn or not was significant, but prediction intervals (PIs) broadly overlapped. Burned sites had a 0.60 detection probability $(95 \%$ PI $=0.46,0.72)$ and unburned sites had a 0.44 probability ( $95 \%$ PI $=0.30,0.59$; Figure 3$)$. Thus, burning somewhat aided the detection of Eastern Massasaugas.

Table 4. Summary statistics from the five variables which comprised the top post hoc model using data from search events on the Eastern Massasauga at Carlyle Lake, Clinton County, Illinois from 2002-2014.

\begin{tabular}{ccccccc}
\hline \multirow{2}{*}{ Variable } & \multirow{2}{*}{ Mean } & SD & Min & Max & \multicolumn{2}{c}{$\mathbf{9 5 \% \text { Confidence Interval }}$} \\
\cline { 5 - 7 } & & & & & Lower & Upper \\
\hline sSUB & 18.12 & 4.52 & -0.10 & 34.00 & 17.79 & 18.45 \\
daRad & 806.34 & 121.91 & 144.00 & 1014.00 & 797.35 & 815.25 \\
m3Min & 5.84 & 4.98 & -7.20 & 19.80 & 5.46 & 6.19 \\
rTime & 0.56 & 0.08 & 0.30 & 0.79 & 0.56 & 0.57 \\
mEffort & 53.19 & 37.38 & 5.00 & 224.00 & 50.41 & 55.90 \\
\hline
\end{tabular}



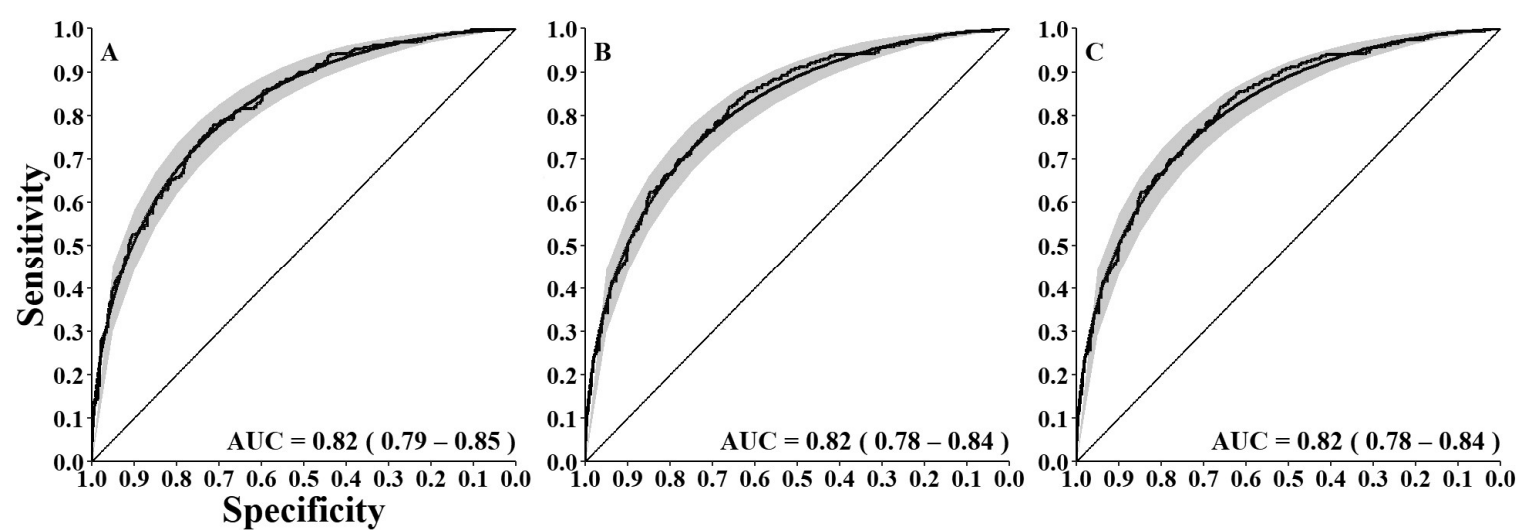

Figure 1. Response operator curves (ROC) for the top and global detection model for the Eastern Massasaugas surveys at Carlyle Lake, Clinton County, Illinois from 2002-2014 where A = the post hoc model, $\mathrm{B}=$ the land manager model, and $\mathrm{C}=$ the global model..

When considering SSUB, the PIs were wider at higher values (due to the lack of surveys over $\sim 30{ }^{\circ} \mathrm{C}$ ) but narrower at cooler temperatures despite having few surveys under those conditions (Table 5; Figures 1 and 2). The general pattern illustrated higher detection probabilities between 18 and $26^{\circ} \mathrm{C}$ (Figure 2). At the lowest sSUB $\left(6.8^{\circ} \mathrm{C}\right)$, detection probabilities were $0.10(95 \% \mathrm{PI}=0.03,0.27)$ but attained a maximum of $0.59(95 \% \mathrm{PI}=0.46,0.72)$ at $23.4^{\circ} \mathrm{C}$ sSUB (Figure 2).

For daRad, the PIs were wide at lower values (due to the lack of surveys at conditions under $\sim 700 \mathrm{~J} / \mathrm{s} \cdot \mathrm{m}^{2}$ ), but the general pattern was a decrease in detection probability with increasing daRad (Table 5; Figures 1 and 2). Detection probabilities for daRad peaked at $0.60(95 \% \mathrm{PI}=0.45,0.73)$ under $\sim 620 \mathrm{~J} / \mathrm{s} \cdot \mathrm{m}^{2}$ (Figure 2). Then, as daRad increased to $1013 \mathrm{~J} / \mathrm{s} \cdot \mathrm{m}^{2}$, detection probabilities decreased to $0.31(95 \%$ PI $=0.16,0.50)$.

As m3Min increased, so did detection probabilities (Figure 3). However, at the extremes of m3Mins, we had greater uncertainty due to fewer surveys above $\sim 18^{\circ} \mathrm{C}$ and below $-1{ }^{\circ} \mathrm{C}$ (Figure 2). With m3Min at $-5.2{ }^{\circ} \mathrm{C}$, we observed relatively high detection probabilities of 0.61 but had little predictive confidence in them (95\% P.I. $=0.37,0.82$; Figure 3). We observed our lowest detection probabilities of $0.52(95 \%$ P.I. $=0.40,0.64)$ at an m3Min of $3.6^{\circ} \mathrm{C}$ (Figure 3). Detection probabilities then steadily increased and peaked at $0.80(95 \% \mathrm{PI}=0.50,0.94)$ when $\mathrm{m} 3 \mathrm{Min}$ was $19.8^{\circ} \mathrm{C}$ (Figure 3 ).

We observed a peak in detection probability around midday, but again had greater uncertainty at earlier and later rTimes due to sampling (Figures 2 and 3). With our earliest surveys at $0716 \mathrm{~h}$, we had a detection probability of $0.25(95 \% \mathrm{PI}=0.06,0.64$; Figure 3$)$. However, detection probabilities were greater than 0.50 between 1042 and $1433 \mathrm{~h}$, with the peak detection of 0.53 (95\% P.I. $=0.41,0.66)$ occurring at $1237 \mathrm{~h}$ (Figure 3). Thereafter, detection probabilities decreased to 0.17 (95\% PI $=0.05,0.46)$ at $1856 \mathrm{~h}$ (Figure 3).

Considering the mean effort per searcher, we observed a sigmoidal increase where detection probabilities had high predictive confidence along the full range of estimates and nearly achieved 1.00 (Figures 2 and 3). At the lowest end of mEffort, 5 min resulted in a 0.22 (95\% PI $=0.14,0.33$ ) detection probability (Figure 3). As mEffort increased, detection probability rapidly increased to $0.50(95 \% \mathrm{PI}=$ $0.37,0.62)$ with $49 \mathrm{~min}$ of $\mathrm{mEffort}$, and a $0.95(95 \% \mathrm{PI}=0.87,0.98)$ detection probability was achieved with 149 min (Figure 3). Additional mEffort showed diminishing returns, whereby a $0.99(95 \% \mathrm{PI}=$ $0.95,1.00)$ probability was achieved at a $196 \mathrm{~min}$ and maxed out at $0.99(95 \% \mathrm{PI}=0.97,1.00)$ at $224 \mathrm{~min}$ (Figure 3). 

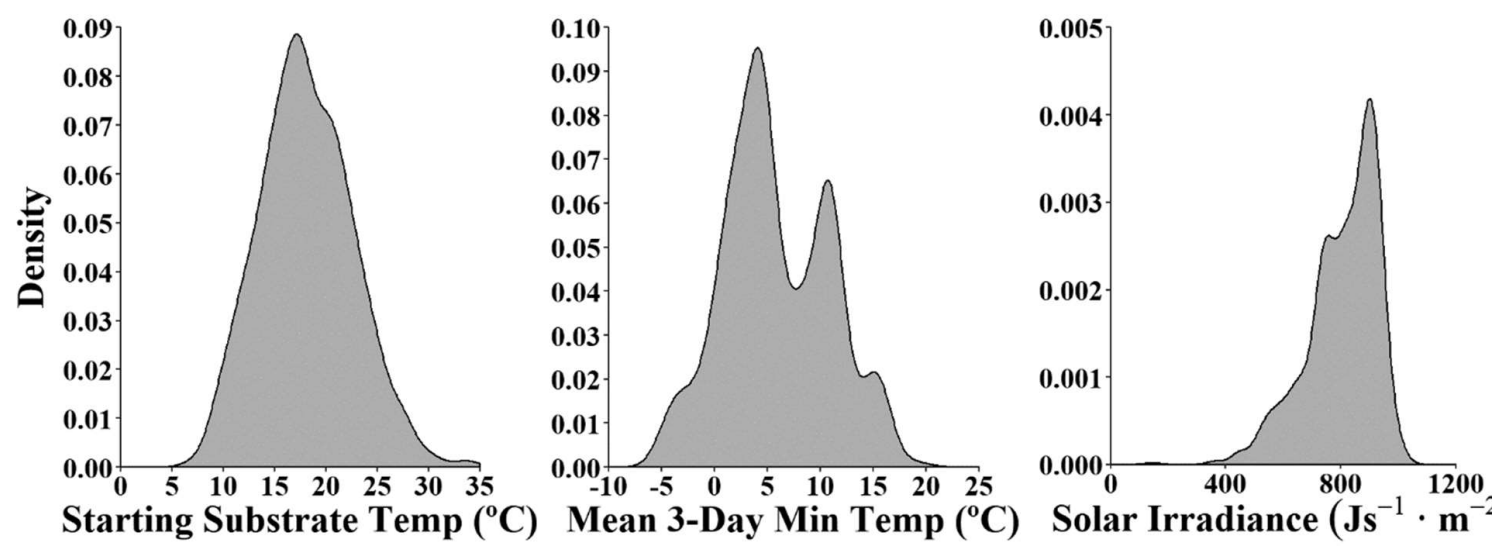

Solar Irradiance $\left(\mathrm{Js}^{-1} \cdot \mathbf{m}^{-2}\right)$
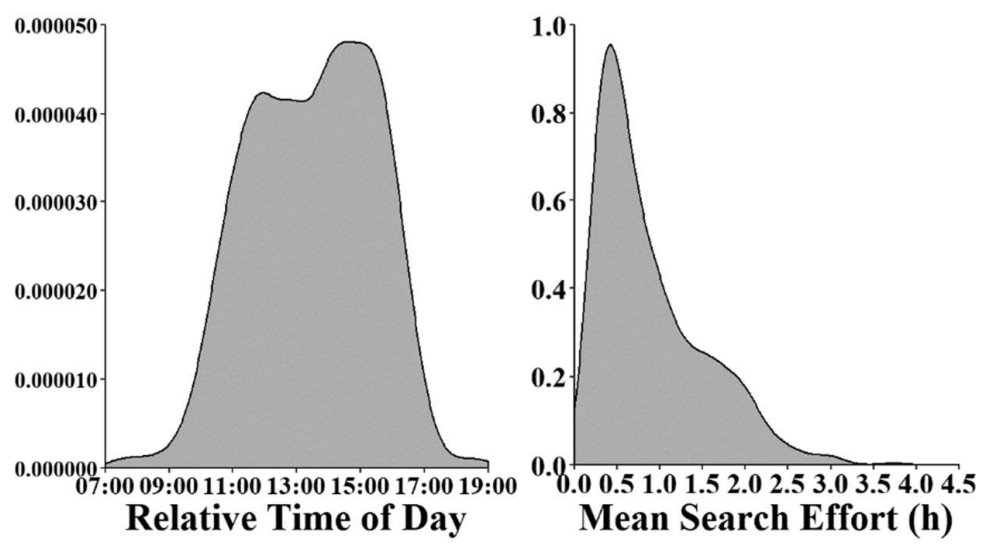

Figure 2. Density plots for the variables retained in the top post hoc detection model to illustrate the variance captured during the surveys.

Table 5. Standardized parameter estimates, standard errors (SE), and confidence intervals (CI) from the top post hoc and Manager binary mixed-effect logistic regressions for detection probability. Data were collected from 713 search events on the Eastern Massasauga at Carlyle Lake, Clinton County, Illinois from 2002-2014. The best parameter model includes only terms with confidence intervals not bounding zero from the global model.

\begin{tabular}{|c|c|c|c|c|c|c|c|c|}
\hline \multirow{2}{*}{ Parameter } & \multicolumn{4}{|c|}{ post hoc $95 \%$ CI } & \multicolumn{4}{|c|}{ Manager $95 \% \mathrm{CI}$} \\
\hline & Estimate & $\mathrm{SE}$ & Lower & Upper & Estimate & SE & Lower & Upper \\
\hline Intercept & 0.40 & 0.28 & -0.15 & 0.96 & 0.31 & 0.27 & -0.22 & 0.85 \\
\hline Burn & -0.65 & 0.28 & -1.19 & -0.10 & -0.65 & 0.28 & -1.19 & -0.11 \\
\hline sSUB & 0.47 & 0.12 & 0.22 & 0.71 & 0.31 & 0.27 & -0.22 & 0.85 \\
\hline sSUB $^{2}$ & -0.20 & 0.07 & -0.34 & -0.06 & -0.65 & 0.28 & -1.19 & -0.11 \\
\hline daRad & -0.36 & 0.13 & -0.62 & -0.10 & - & - & - & - \\
\hline $\mathrm{daRad}^{2}$ & -0.11 & 0.07 & -0.25 & 0.03 & - & - & - & - \\
\hline m3Min & 0.11 & 0.11 & -0.11 & 0.32 & 0.31 & 0.27 & -0.22 & 0.85 \\
\hline $\mathrm{m} 3 \mathrm{Min}^{2}$ & 0.12 & 0.09 & -0.05 & 0.30 & -0.65 & 0.28 & -1.19 & -0.11 \\
\hline rTime & -0.14 & 0.11 & -0.35 & 0.07 & 0.31 & 0.27 & -0.22 & 0.85 \\
\hline rTime ${ }^{2}$ & -0.16 & 0.08 & -0.32 & 0.00 & -0.65 & 0.28 & -1.19 & -0.11 \\
\hline mEffort & 1.07 & 0.13 & 0.81 & 1.33 & 0.31 & 0.27 & -0.22 & 0.85 \\
\hline
\end{tabular}



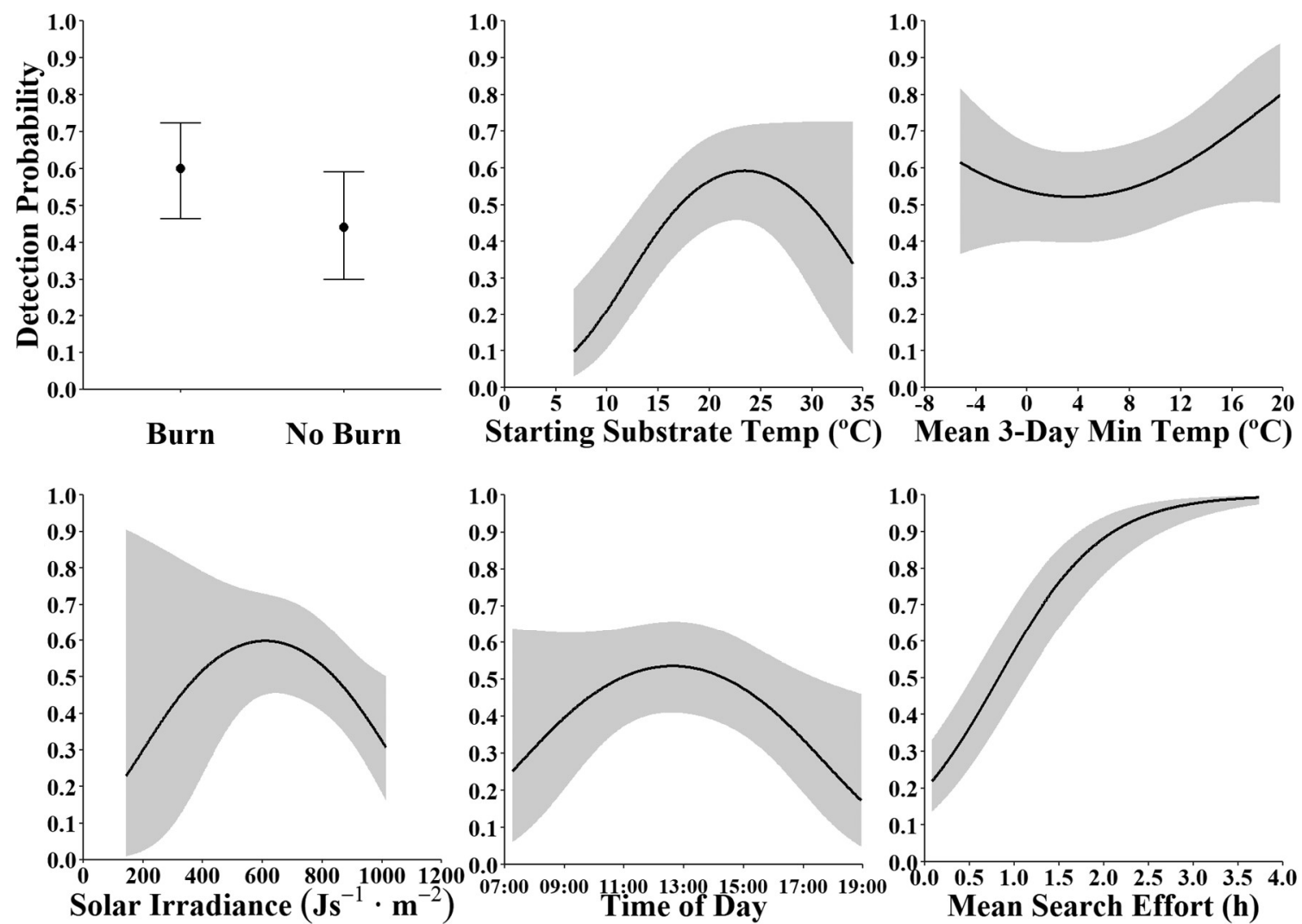

Figure 3. The effects of environmental, temporal, and effort co-variates on the detection probability of Eastern Massasaugas generated from 713 search events at Carlyle Lake, Clinton County, Illinois from 2002-2014.

\subsection{Conservation Applications}

Our detection probability tool offers all input variables from the Manager model (white cells) and allows the calculation of mEffort using nSearch and the planned tEffort for the event (Figure 4). To calculate the number of searches required, we allow the user to enter their desired probability of detecting an Eastern Massasauga (Figure 4). The tool will also produce warnings if a user attempts to enter values outside the bounds modeled (Figure 4). All transformations and calculations are available, but not modifiable (gray cells), to the user on the second page of the workbook (Figure S3, Supplementary Materials). In our example, we planned a search in burned habitat, starting at $1326 \mathrm{~h}$, with a goal of $1 \mathrm{~h}$ of effort per searcher ( 4 total h). Given an sSUB of 16.2 and an m3Min of 12.5, we predicted our detection probability to be 0.67 (95\% CI 0.40, 0.86). Thus, we would need 4-20 surveys under similar conditions to achieve a $95 \%$ chance of detecting an Eastern Massasauga in at least one survey (Figure 4).

Initially, we had 58 surveys for the Chicago Region site; however, 12 had combinations of values with lower sSUB and daRad, and higher values of mEffort than we modeled and, thus, were removed from the analysis leaving 46 surveys (Table S3, Supplementary Materials). The overall probability presence but no detections for Eastern Massasaugas at the site varied from $2.56 \times 10^{-5}$ to $2.54 \times 10^{-28}$ by year (Table 6). When considering all surveys, the probability was $2.56 \times 10^{-46}\left(95 \% \mathrm{CI}, 1.17 \times 10^{-83}\right.$, $3.90 \times 10^{-26}$ ) or, roughly, an average of a one in $1.64 \times 10^{45}$ chance (Table 6). Thus, if our model applies to other grassland habitats, and depending on the threshold decided by the governing land management agency, the site can likely be declared extirpated for management purposes. 


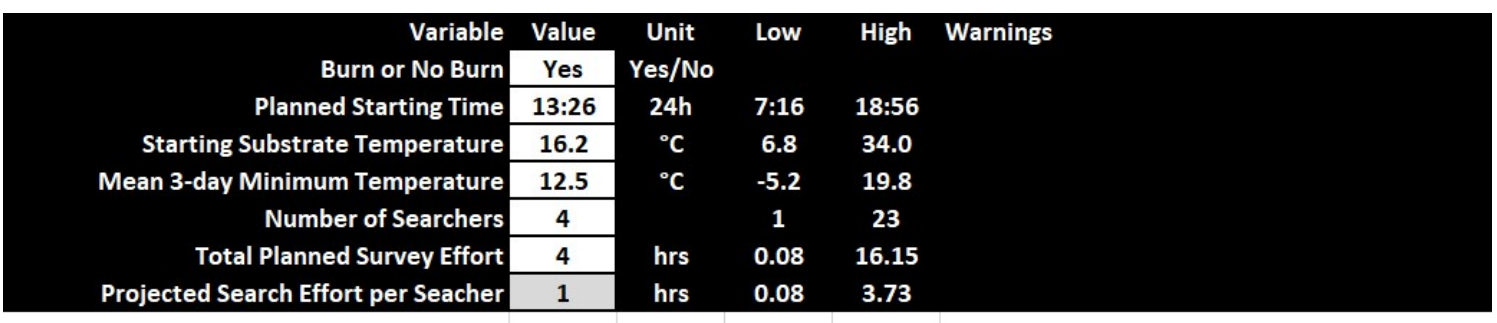

\begin{tabular}{|r|c|c|c|}
\hline & \multicolumn{3}{c|}{$95 \%$ C.I. } \\
& Mean & \multicolumn{1}{c|}{ Lower } & Upper \\
\hline Detection Probability & 0.670 & 0.403 & 0.859 \\
\hline Probability of an Assumed False Negative & 0.330 & 0.141 & 0.597 \\
\hline Desired Probability of Detection in Surveys & 0.95 & 0.95 & 0.95 \\
\hline Number of Searches & 8 & 4 & 20 \\
\hline
\end{tabular}

Figure 4. Screenshot of the spreadsheet-based detection tool for grassland Eastern Massasauga surveys. Forecasted values are entered to estimate the detection/non-detection probabilities and the number of searches required to achieve a threshold level of detection assuming a site is occupied.

Table 6. Overall probabilities and chances that Eastern Massasaugas were not detected during surveys at a historic site in the Chicago region, Illinois, United States of America (USA) (Table S3, Supplementary Materials), assuming the site was occupied.

\begin{tabular}{ccccccc}
\hline \multirow{2}{*}{ Year } & \multicolumn{2}{c}{ Probability Missed but Present } & \multicolumn{3}{c}{ Odds Missed but Present } \\
\cline { 2 - 7 } & Mean & Lower & Upper & Mean & Lower & Upper \\
\hline 2008 & $2.54 \times 10^{-28}$ & $1.29 \times 10^{-16}$ & $1.46 \times 10^{-50}$ & $1: 3.94 \times 10^{27}$ & $1: 7.77 \times 10^{15}$ & $1: 6.84 \times 10^{49}$ \\
2009 & $2.56 \times 10^{-5}$ & $4.40 \times 10^{-4}$ & $7.92 \times 10^{-11}$ & $1: 3.91 \times 10^{4}$ & $1: 2.27 \times 10^{3}$ & $1: 1.26 \times 10^{10}$ \\
2010 & $5.23 \times 10^{-6}$ & $1.74 \times 10^{-3}$ & $6.88 \times 10^{-9}$ & $1: 1.91 \times 10^{5}$ & $1: 5.73 \times 10^{2}$ & $1: 1.45 \times 10^{8}$ \\
2015 & $1.80 \times 10^{-8}$ & $3.95 \times 10^{-4}$ & $1.46 \times 10^{-15}$ & $1: 5.57 \times 10^{7}$ & $1: 2.53 \times 10^{3}$ & $1: 6.84 \times 10^{14}$ \\
Overall & $6.09 \times 10^{-46}$ & $3.90 \times 10^{-26}$ & $1.17 \times 10^{-83}$ & $1: 1.64 \times 10^{45}$ & $1: 2.57 \times 10^{25}$ & $1: 8.58 \times 10^{82}$ \\
\hline
\end{tabular}

\section{Discussion}

Sit-and-wait foraging snakes (such as the Eastern Massasauga), which are inactive for long periods, might not be efficiently sampled using traps or artificial cover objects $[43,44]$; however, there is some indication that passive sampling can provide supplementary data [45]. Relatively inactive species are best sampled using time- and/or area-constrained searches. However, determining parameters influencing detectability becomes of paramount importance in the design and implementation of survey and monitoring programs. We found three abiotic parameters (solar irradiance, substrate temperature, mean three-day minimum air temperature), two search parameters (effort per searcher and time of day), and one management related parameter (burns) which significantly influenced detection of Eastern Massasaugas.

\subsection{Modeled Effects}

Detection probabilities were slightly higher for surveys in burned habitat (either full or partial). Burning is typically used as a management tool in Eastern Massasauga habitat to maintain early successional vegetation [46]. Eastern Massasaugas do not show alterations in movements, home ranges, or habitat use associated with burns, but do select habitat characteristics favoring thermoregulation [47]. Thus, they are likely more observable thermoregulating during the spring emergence period from greater distances in burned compared to unburned habitats. Timing or pairing visual encounter surveys (VES) with management burns can be an effective tool for increasing the chances of detection. However, caution must be exercised when burning after snakes emerge, which could cause significant mortality [46,47]. 
Both substrate temperature and mean three-day minimum air temperature influenced detection probability of Eastern Massasaugas in our study system. Such thermal relationships are expected for an ectothermic vertebrate. Harvey [48] found that Eastern Massasaugas in a Canadian population were more detectable at intermediate body temperatures $\left(20-30^{\circ} \mathrm{C}\right)$ and when they were more visible $(>75 \%$ body exposure). Furthermore, he found that weather conditions which expressed thermoregulatory behavior (e.g., slightly cooler, sunny days) for intermediate body temperatures also resulted in increased detectability.

In contrast to other studies of snakes in Europe and North America, we did not find a significant positive effect of day of year on detection probability. In the Jura Mountains of Europe (France and Switzerland), Kéry [4] found a unimodal relationship between day of year and detection probability for three species of snakes (Asp Viper Vipera aspis; Smooth Snake Coronella austriaca; Grass Snake Natrix natrix), and the same unimodal relationship was found in North America for both Banded Watersnakes (Nerodia fasciata) and Black Swamp Snakes (Seminatrix pygaea; [49]). However, the Banded Watersnake and Black Swamp Snake were primarily sampled with passive trapping throughout a full season. Still, it is possible that such a trend may have emerged for Eastern Massasaugas if we sampled throughout the active season. Our data do suggest that fluctuations in environmental temperatures as the day of year progresses can result in successful search periods outside of the spring emergence period, and season and/or day of year might not always be a good proxy for environmental temperatures.

Detection probabilities of Eastern Massasaugas decreased as solar irradiance increased, and a similar pattern was also observed for the time of day. Although the two metrics are not significantly intercorrelated, solar irradiance peaks at astronomical noon, as well as throughout the activity season (strongest during the peak of summer), but it becomes uncoupled in overcast situations. During the spring and early summer, Eastern Massasaugas bask in the morning [29], which explains our increased detection rates early in the day. As temperatures increase, there is less need to bask; thus, they become more crepuscular and cryptic during the hottest periods of the year. Our decline in detection rates illustrates the reduced need for basking during periods when shaded air temperatures are greater than $24{ }^{\circ} \mathrm{C}$. A similar trend was found by Erb et al. [7] for Eastern Box Turtles (Terrapene carolina), which had significantly higher detection rates earlier in the day. However, the pattern does not hold for all reptile species. Common Skink (Oligosoma polychroma) detections in New Zealand were the highest and least variable at ambient temperatures $\left(12-18{ }^{\circ} \mathrm{C}\right)$ during daytime hours and did not decline until the evening [50].

We found that detection increased as search effort within a visit increased, but there were diminishing returns. Survey duration within a visit can significantly influence detection values in some, but not all, reptiles [5]. Furthermore, increasing survey duration was found to increase the power to detect raptor migration trends [51] and increase the number of species detected in anuran call surveys [52]. While search effort is incorporated into detection estimates, the effects of search area size are less commonly investigated. For Eastern Massasaugas, we did not find a relationship between search area size and detection probabilities. Our result is similar to Kéry [4], who found no effect of search area on the detection of three common snake species in Europe, although he did find that detection rates increased as population sizes increased. For relatively common species, one would expect higher detection rates when population sizes are larger since there is a greater chance of encountering the organism. Endangered species often have reduced numbers across the landscape and, therefore, can have small population numbers regardless of patch size. In this instance, if population size remains relatively constant across patches, but patch sizes increase, we would expect detection rates to decrease as the survey area increases [53]. Therefore, the next step might be to examine the interrelationship between density/abundance, patch size, and detection probabilities. Overall, our results highlight and reinforce the need to maximize search effort for endangered species.

Numerous other survey methods were used across the Eastern Massasauga's range, including road cruising, drift fences, and cover board arrays. Researchers were effective at encountering enough individuals using drift fence-funnel trap arrays for radio-telemetry studies of Eastern and Western 
Massasaugas $[46,47]$. The only study to directly compare multiple methods found that effort required (in person-hours) is lower for the more passive methods of carpet squares, cover boards, and drift fences [45]. The study also found sex-specific behavioral biases with females more likely to be encountered using coverboards and males more likely to be encountered with drift fences [45]. The overall results do recommend the use of multiple encounter methods for monitoring projects [45], and further work could be done to examine how detection probabilities differ among methods.

As MacKenzie et al. [24] pointed out, rare and imperiled species are simultaneously the species most in need of information on state variables (e.g., occupancy, abundance) and vital rates, and the species for which such information is the most difficult to obtain. Imperfect detection probability (i.e., the probability of detecting a species when present is less than one) must be accounted for when estimating state variables $[24,54]$. While detection rates can covary with predictor variables, detection probability often is treated as a nuisance variable in the occupancy or abundance modeling process $[55,56]$. However, by focusing on detection probability, researchers can evaluate the effects of sampling covariates such as abiotic factors, sampling method, and survey type $[6,57,58]$. Furthermore, this information can be used to determine the minimum number of visits required to a site to declare absence with a given level of confidence [4,27], which is a crucial first step in the development of survey protocols and monitoring programs.

The model we constructed provides good predictive capacity, but it was derived from the southern range limit in grassland habitat for a species with a historically broad distribution [29,59]. Over their broad range, Eastern Massasaugas occupy habitats ranging from wet to dry grasslands throughout the Midwest, to bogs, fens, and peatlands in the Great Lakes region, to open woodlands in northern Michigan and parts of Canada $[29,59]$. Therefore, not only may clinal variation exist but also variation due to habitat preferences. Thus, our model may only have the predictive capacity for grassland sites in the lower Midwest. We encourage the repetition of the methods and validation of the model across the species' range.

The only previous study examining detection in Eastern Massasaugas used 54 search events over two years from May-August paired with radio-equipped snakes [60]. From their 11 detections, they found detection probabilities approached 1.00 when the per searcher effort exceeded $90 \mathrm{~min}$ [60], similar to our study. However, they did not find the strong coupling with temperatures we found, and although they found that detection probabilities approached 0.80 on cooler mornings, confidence intervals were wide [60]. Future designs should also include stage classes as some stage classes may be more readily detectable than others as males tend to move more, gravid females tend to bask more often during gestation, and neonates/juveniles are extremely cryptic.

\subsection{Conservation Applications}

Giving a 0.10 spread from the maximal detection probability (in parentheses) up to a 0.95 probability for each variable, our data for Eastern Massasaugas indicate that, to maximize detection efficiency, surveys should be conducted preferably in burned habitat, between 9:30 and 16:00 h (0.43-0.50), between substrate temperatures of 16.7 and $30.2^{\circ} \mathrm{C}(0.49-0.59)$, and between mean minimum three-day temperatures of 15.9 and $19.7^{\circ} \mathrm{C}(0.70-0.80)$, under overall solar radiation of $373-844 \mathrm{~J} / \mathrm{s} \cdot \mathrm{m}^{2}(0.50-0.60)$, for 1.8-2.4 h (0.85-0.95) per searcher. Under the Manager model (excluding daRad), the combinations of variables we present above should result in mean detection probabilities from 0.88 to 0.96 , but with greater uncertainty.

To simplify the decision-making process for Eastern Massasauga surveys, we developed a spreadsheet-based detection tool as a guide. A researcher or land manager can enter forecasted values for the significant parameters that influenced Eastern Massasauga detection and determine the probability of detection for the upcoming survey, as well as the mean number of searches required. Additionally, one can estimate detection probability after the survey by entering the actual parameter values recorded during the sampling period. Such data could be used to determine if a site should be declared extirpated for management purposes. However, we do caution the use of the model outside 
of grassland habitats and, potentially, the region itself until it is further validated range-wide for the species. Given the decline of numerous snake species around the world, there is an urgent need to establish current status and distribution states for species of conservation concern. To deploy resources (i.e., time and money) in a cost-effective manner, and avoid wasted effort to establish presence or extirpation at a given site, we anticipate that our spreadsheet-based detection tool can be modified to meet the needs for other species.

\section{Conclusions}

As the current biodiversity crisis continues [61], the need for cost-effective use of resources and scientific expertise will be increasingly important [5]. When population declines are suspected, it is often difficult to separate true absence from inadequate sampling without incorporating detection probabilities; this is especially true for imperiled and/or cryptic species. However, in many cases, existing datasets can be leveraged to provide insight and starting points for imperiled species survey and monitoring programs. We encourage other researchers to use their datasets to examine factors influencing detection rates, which will be useful for designing and implementing regional survey and monitoring programs. These types of analyses will ensure that conservation and management agencies will have the necessary information to make informed decisions when surveying and monitoring for imperiled and cryptic species.

Supplementary Materials: The following are available online at http://www.mdpi.com/1424-2818/12/5/177/s1: Table S1. Final results of ridge regression analysis showing the stability in parameter estimates for all variables retained in the detection analysis of Eastern Massasauga searches conducted at Carlyle Lake, Clinton County, Illinois, from 1999-2014; Table S2. Number of annual surveys conducted at each major site which had complete survey-specific data and were used in the detection analysis of Eastern Massasaugas at Carlyle Lake, Clinton County, Illinois; Table S3. Historical Eastern Massasauga search data for four years of searching at a site in the Chicago, Illinois, USA, region with the standardized search variables, predicted detection and non-detection probabilities, and associated 95\% confidence intervals (Lower and Upper). All variable abbreviations can be found in Table 1; Figure S1. Pearson Correlation analysis of all candidate variables to be used for the detection probability analysis of Eastern Massasaugas from fieldwork at Carlyle Lake, Clinton County, Illinois during the 1999-2014 field seasons; Figure S2. Ridge regression plot to determine the multicollinearity of environmental and temporal variables used in analyses. Variable abbreviations can be found in Table 1; Figure S3. Example screenshot of the calculation sheet for the spreadsheet-based detection tool for Eastern Massasauga surveys. All calculated values are there for reference to see how calculations were made and are not editable; Excel workbook titled Final_Massasauga_Detection_Tool.xlsx as a companion guide for use in surveys.

Author Contributions: Specific contributions are as follows: conceptualization, J.A.C. and M.J.D.; data curation, M.J.D. and S.J.B.; formal analysis, M.J.D. and W.E.P.; funding acquisition, M.J.D., S.J.B., and C.A.P.; investigation, M.J.D. and S.J.B.; methodology, M.J.D. J.A.C., and W.E.P.; project administration, M.J.D.; resources, M.J.D., S.J.B., and C.A.P.; software, M.J.D., and W.E.P.; supervision, S.J.B. and M.J.D.; validation, M.J.D.; visualization, M.J.D.; writing — original draft preparation, J.A.C. and M.J.D.; writing—review and editing, J.A.C., M.J.D, W.E.P., S.J.B., and C.A.P. All authors have read and agreed to the published version of the manuscript.

Funding: We thank the Illinois Department of Natural Resources, US Fish and Wildlife Service, US Army Corps of Engineers, Illinois State Toll Highway Authority, and the Chicago Herpetological Society for funding this project.

Acknowledgments: We thank S. Ballard, J. Birdsell, K. Boyles, J. Bunnell, M. Kemper, and G. Tatham of the Illinois Department of Natural Resources, and D. Baum and J. Smothers of the US Army Corps of Engineers, without whom we could not have accomplished much of this work. We thank the many field workers and volunteers who helped us capture snakes since 1999. Most notably, we appreciate the efforts of B. Jellen, A. Kuhns, J. Mui, D. Shepard, A. Stites, J. Warner, and D. Wylie.

Conflicts of Interest: The authors declare no conflicts of interest. The funders had no role in the design of the study; in the collection, analyses, or interpretation of data; in the writing of the manuscript; or in the decision to publish the results.

\section{References}

1. Haughland, D.L.; Hero, J.M.; Schieck, J.; Castley, J.G.; Boutin, S.; Solymos, P.; Lawson, B.E.; Holloway, G.; Magnusson, W.E. Planning forwards: Biodiversity research and monitoring systems for better management. Trends Ecol. Evol. 2010, 25, 199-200. [CrossRef] [PubMed] 
2. McDonald, L.L. Sampling rare populations. In Sampling Rare or Elusive Species: Concepts, Designs, and Techniques for Estimating Population Parameters; Thompson, W.L., Ed.; Island Press: Washington, DC, USA, 2004; pp. 11-42.

3. Rizkalla, C.E.; McCoy, E.D.; Britt, E.J.; Mushinsky, H.R. Indirect monitoring of a rare lizard: Effects of sampling intensity, season, and management practices. Herpetol. Conserv. Biol. 2015, 10, 894-903.

4. Kéry, M. Inferring the absence of a species-A case study of snakes. J. Wildl. Manag. 2002, 66, 330-338. [CrossRef]

5. Sewell, D.; Guillera-Arroita, G.; Griffiths, R.A.; Beebee, T.J.C. When is a species declining? Optimizing survey effort to detect population changes in reptiles. PLOS ONE 2012, 7, e43387. [CrossRef]

6. Perkins, G.C.; Kutt, A.S.; Vanderduys, E.P.; Perry, J.J. Evaluating the costs and sampling adequacy of a vertebrate monitoring program. Aust. Zool. 2013, 36, 373-380. [CrossRef]

7. Erb, L.A.; Willey, L.L.; Johnson, L.M.; Hines, J.E.; Cook, R.P. Detecting long-term population trends for an elusive reptile species. J. Wildl. Manag. 2015, 79, 1062-1071. [CrossRef]

8. Gibbons, J.W.; Scott, D.E.; Ryan, T.J.; Buhlmann, K.A.; Tuberville, T.D.; Metts, B.S.; Greene, J.L.; Mills, T.; Leiden, Y.; Poppy, S. The global decline of reptiles, déjà vu amphibians. BioScience 2000, 50, 653-666. [CrossRef]

9. Araújo, M.B.; Thuiller, W.; Pearson, R.G. Climate warming and the decline of amphibians and reptiles in Europe. J. Biogeogr. 2006, 33, 1712-1728. [CrossRef]

10. Todd, B.; Willson, J.; Gibbons, J. The global status of reptiles and causes of their decline. In Ecotoxicology of Reptiles and Amphibians; Sparling, D., Linder, G., Bishop, C., Krest, S., Eds.; SETAC Press: Pensacola, FL, USA, 2010; pp. 48-61.

11. IUCN Summary Statistics. Available online: http://www.iucnredlist.org/info/hold/facts-and-figures/ summary-statistics (accessed on 6 September 2016).

12. Mullin, S.J.; Seigel, R.A. Snakes: Ecology and Conservation; Cornell University Press: Ithaca, NY, USA, 2009.

13. Illinois Department of Natural Resources Wildlife Action Plan. Available online: https://www.dnr.illinois. gov/conservation/IWAP/Pages/default.aspx (accessed on 12 September 2019).

14. Godley, J.S. Foraging ecology of the striped swamp snake, Regina alleni, in southern Florida. Ecol. Monogr. 1980, 50, 411-436. [CrossRef]

15. Dorcas, M.E.; Willson, J.D.; Reed, R.N.; Snow, R.W.; Rochford, M.; Miller, M.A.; Meshaka, W.E., Jr.; Andreadis, P.T.; Mazzotti, F.J.; Romagosa, C.M.; et al. Severe mammal declines coincide with python proliferation in Everglades National Park. Proc. Nat. Acad. Sci. USA 2012, 109, 2418-2422. [CrossRef]

16. Willson, J.D.; Winne, C.T. Evaluating the functional importance of secretive species: A case study of aquatic snake predators in isolated wetlands. J. Zool. 2016, 29, 266-273. [CrossRef]

17. Zipkin, E.F.; DiRenzo, G.V.; Ray, J.M.; Rossman, S.; Lips, K.R. Tropical snake diversity collapses after widespread amphibian loss. Science 2020, 367, 814-816. [CrossRef] [PubMed]

18. Reading, C.J.; Luiselli, L.M.; Akani, G.C.; Bonnet, X.; Amori, G.; Ballouard, J.M.; Filippi, E.; Naulleau, G.; Pearson, D.; Rugiero, L. Are snake populations in widespread decline? Biol. Lett. 2010, 23, 777-780. [CrossRef] [PubMed]

19. Parker, W.S.; Plummer, M.V. Population ecology. In Snakes: Ecology and Evolutionary Biology; Seigel, R.A., Collins, J.T., Novak, S.S., Eds.; The Blackburn Press: Caldwell, NJ, USA, 1987; pp. 253-301.

20. Steen, D.A. Snakes in the grass: Secretive natural histories defy both conventional and progressive statistics. Herpetol. Conserv. Biol. 2010, 5, 183-188.

21. Durso, A.M.; Willson, J.D.; Winne, C.T. Needles in haystacks: Estimating detection probability and occupancy of rare and cryptic snakes. Biol. Conserv. 2011, 144, 1508-1515. [CrossRef]

22. Jenkins, C.L.; Peterson, C.R.; Kingsbury, B.A. Modeling snake distribution and habitat. In Snakes: Ecology and Conservation; Mullin, S.J., Seigel, R.A., Eds.; Cornell University Press: Ithaca, NY, USA, 2009; pp. 123-148.

23. Böhm, M.; Collen, B.; Baillie, J.; Bowles, P.; Chanson, J.; Cox, N.; Hammerson, G.; Hoffmann, M.; Livingstone, S.; Ram, M.; et al. The conservation status of the world's reptiles. Biol. Conserv. 2013, 157, 372-385.

24. MacKenzie, D.I.; Nichols, J.D.; Sutton, N.; Kawanishi, K.; Bailey, L.L. Improving inferences in population studies of rare species that are detected imperfectly. Ecology 2005, 86, 1101-1113. [CrossRef]

25. Mazerolle, M.J.; Bailey, L.L.; Kendall, W.L.; Royle, J.A.; Converse, S.J.; Nichols, J.D. Making great leaps forward: Accounting for detectability in herpetological field studies. J. Herpetol. 2007, 41, 672-689. [CrossRef] 
26. Kellner, K.F.; Swihart, R.K. Accounting for imperfect detection in ecology: A quantitative review. PLoS ONE 2014, 9, e111436. [CrossRef]

27. Durso, A.M.; Seigel, R.A. A snake in the hand is worth 10,000 in the bush. J. Herpetol. 2015, 49, 503-506. [CrossRef]

28. MacKenzie, D.I.; Royle, J.A. Designing occupancy studies: General advice and allocating survey effort. J. Appl. Ecol. 2005, 42, 1105-1114. [CrossRef]

29. Ernst, C.H.; Ernst, E.M. Snakes of the United States and Canada; Smithsonian Institution: Washington, DC, USA, $2003 ;$ p. 668.

30. Species Status Assessment for the Eastern Massasauga Rattlesnake (Sistrurus catenatus). Available online: https://www.scienceapplications.org/pluginfile.php/375/block_html/content/SSA_Eastern\% 20MassasaugaRattlesnake_201607.pdf (accessed on 23 June 2015).

31. U.S. Fish and Wildlife Service. Endangered and threatened wildlife and plants: Threatened species status for the eastern massasauga rattlesnake. Fed. Regist. 2015, 80, 58688-58701.

32. U.S. Fish and Wildlife Service. Endangered and threatened wildlife and plants; threatened species status for the eastern massasauga rattlesnake. Fed. Regist. 2016, 81, 67193-67214.

33. Species at Risk Public Registry: Massasauga Species Profile. Available online: http://www.sararegistry.gc.ca/ species/speciesDetails_e.cfm?sid=277 (accessed on 6 September 2016).

34. Shepard, D.B.; Dreslik, M.J.; Jellen, B.C.; Phillips, C.A. Reptile road mortality around an oasis in the Illinois corn desert with emphasis on the endangered eastern massasauga. Copeia 2008, 2008, 350-359. [CrossRef]

35. Venables, W.N.; Ripley, B.D. Modern Applied Statistics., 4th ed.; Springer: New York, NY, USA, 2002; p. 498.

36. R: A Language and Environment for Statistical Computing. Available online: https://www.gbif.org/tool/ 81287/r-a-language-and-environment-for-statistical-computing (accessed on 10 February 2015).

37. Bates, D.; Maechler, M.; Bolker, B.; Walker, S. Fitting linear mixed-effects models using lme4. J. Stat. Soft. 2015, 67, 1-48. [CrossRef]

38. Burnham, K.P.; Anderson, D.R. Model Selection and Inference: A Practical Information-Theoretic Approach; Springer: New York, NY, USA, 2002; p. 355.

39. AICcmodavg: Model Selection and Multimodel Inference Based on (Q)AIC(c). Available online: https: //cran.r-project.org/web/packages/AICcmodavg/index.html (accessed on 10 February 2015).

40. Fox, J. Effect displays in R for generalised linear models. J. Stat. Soft. 2003, 8, 1-27. [CrossRef]

41. Fox, J.; Hong, J. Effect displays in R for multinomial and proportional-odds logit models: Extensions to the effects package. J. Stat. Soft. 2009, 32, 1-24. [CrossRef]

42. Lefcheck, J.S. piecewiseSEM: Piecewise structural equation modeling in $\mathrm{R}$ for ecology, evolution, and systematics. Methods Ecol. Evol. 2016, 7, 573-579. [CrossRef]

43. Fitch, H.S. Methods of sampling snake populations and their relative success. Herpetol. Rev. 1992, 23, 17-19.

44. Ryan, T.J.; Philippi, T.; Leiden, Y.A.; Dorcas, M.E.; Wigley, T.B.; Gibbons, J.W. Monitoring herpetofauna in a managed forest landscape: Effects of habitat types and census techniques. For. Ecol. Manag. 2002, 167, 83-90. [CrossRef]

45. Bartman, J.F.; Kudla, K.; Bradke, D.R.; Otieno, S.; Moore, J.A. Work smarter not harder: Comparison of visual and trap survey methods for the eastern Massasauga rattlesnake (Sistrurus catenatus). Herp. Cons. Biol. 2016, 11, 451-458.

46. Durbian, F.F. Effects of mowing and summer burning on the massasauga (Sistrurus catenatus). Am. Midl. Nat. 2006, 155, 329-334. [CrossRef]

47. Cross, M.D.; Root, K.V.; Mehne, C.J.; McGowan-Stinski, J.; Pearsall, D.; Gillinham, J.C. Multi-scale responses of eastern Massasauga rattlesnakes (Sistrurus catenatus) to prescribed fire. Am. Midl. Nat. 2016, 173, 346-362. [CrossRef]

48. Harvey, D.S. Detectability of a large-bodied snake (Sistrurus c. catenatus) by time-constrained searching. Herpetol. Rev. 2005, 36, 413-415.

49. Willson, J.D.; Winne, C.T.; Todd, B.D. Ecological and methodological factors affecting detectability and population estimation in elusive species. J. Wildl. Manag. 2011, 75, 36-45. [CrossRef]

50. Hoare, J.M.; O’Donnell, C.F.J.; Westbrooke, I.; Hodapp, D.; Lettink, M. Optimising the sampling of skinks using artificial retreats based on weather conditions and time of day. Appl. Herpetol. 2009, 6, 379-390.

51. Lewis, S.A.; Gould, W.R. Survey effort effects on power to detect trends in raptor migration counts. Wildl. Soc. Bull. 2000, 28, 317-329. 
52. Shirose, L.J.; Bishop, C.A.; Green, D.M.; MacDonald, C.J.; Brooks, R.J.; Helferty, N.J. Validation tests of an amphibian call count survey technique in Ontario, Canada. Herpetologica 1997, 53, 312-320.

53. Tanadini, L.G.; Schmidt, B.R. Population size influences amphibian detection probability: Implications for biodiversity monitoring programs. PLOS ONE 2011, 6, e28244. [CrossRef]

54. MacKenzie, D.I.; Nichols, J.D.; Lachman, G.B.; Droege, S.; Royle, J.A.; Langtimm, C.A. Estimating site occupancy rates when detection probabilities are less than one. Ecology 2002, 83, 2249-2255. [CrossRef]

55. Christy, M.T.; Adam, A.A.Y.; Rodda, G.H.; Savidge, J.A.; Tyrell, C. Modeling detection probability to evaluate management and control tolls for an invasive species. J. Appl. Ecol. 2010, 47, 106-113. [CrossRef]

56. Steen, D.A.; McClure, C.J.W.; Brock, J.C.; Rudolph, D.C.; Pierce, J.B.; Lee, J.R.; Humphries, W.J.; Gregory, B.B.; Sutton, W.B.; Smith, L.L.; et al. Landscape-level influences of terrestrial snake occupancy within the southeastern United States. Ecol. Appl. 2012, 22, 1084-1097. [CrossRef]

57. Bailey, L.L.; Simons, T.R.; Pollock, K.H. Estimating site occupancy and species detection probability parameters for terrestrial salamanders. Ecol. Appl. 2004, 14, 692-702. [CrossRef]

58. Edwards, E.; Pauley, T.K.; Waldron, J.L. Estimating spring salamander detection probability using multiple models. J. Herpetol. 2016, 50, 126-129. [CrossRef]

59. Ernst, C.H.; Ernst, E.M. Venomous reptiles of the United States, Canada, and Northern Mexico; Volume 1 Heloderma, Micruroides, Micrurus, Pelamis, Agkistrodon, Sistrurus; The Johns Hopkins University Press: Baltimore, MD, USA, 2011; p. 352.

60. Shaffer, S.A.; Roloff, G.J.; Campa III, H. Survey methodology for detecting Massasauga rattlesnakes in southern Michigan. Wildl. Soc. Bull. 2019, 43, 508-514. [CrossRef]

61. Ceballos, G.; Ehrlich, P.R.; Barnosky, A.D.; García, A.; Pringle, R.M.; Palmer, T.M. Accelerated modern human-induced species losses: Entering the sixth mass extinction. Sci. Adv. 2015, 1, e1400253. [CrossRef]

(C) 2020 by the authors. Licensee MDPI, Basel, Switzerland. This article is an open access article distributed under the terms and conditions of the Creative Commons Attribution (CC BY) license (http://creativecommons.org/licenses/by/4.0/). 